\title{
The Relationship Between Burnout and Self-Efficacy among Iranian Male and Female EFL Teachers
}

\begin{abstract}
Ali Roohani, Mehdi Iravani
Shahrekord University

Correspondence concerning this article should be addressed to Ali Roohani, English Department, Faculty of Letters \& Humanities, Shahrekord University, the 2nd Kilometer of Saman Road, Shahrekord, Iran. Zip Code: 88186/34141, P.O. Box: 115. E-mail: roohani.ali@gmail.com

Teaching is a job marked by high levels of burnout. Teacher burnout has been extinsively studied in connection with other important psychological qualities, such as perceived selfefficacy. However, little research has examined this relationship among teachers in the English as a foreign language (EFL) context. In this light, this mixed-method study was intended to a) investigate the relationship between the degree of perceived self-efficacy by Iranian EFL teachers and their professional burnout level, and b) see whether gender could make a significant difference in the teachers' burnout level. To these ends, 80 male and female Iranian EFL teachers from several high schools in Isfahan, selected through convenience sampling, participated in the study and responded to the Maslach Burnout Inventory-Educator's Survey (MBI-ES) and a modified version of Teacher Sense of Efficacy Scale (TSES). To triangulate the data, a semi-structured interview was also conducted with 15 teachers. Correlational and $t$-test data analysis showed that there was a strong significant correlation between the participants' perceived self-efficacy and their burnout level in a negative direction. The gender variable also had a modifying effect on the teachers' burnout. Female teachers, in fact, had a lower burnout level. The follow-up interview further confirmed the relationship and revealed the three main themes of mental fatigue, contact avoidance, and stress in explaining teacher burnout. The implications for school administrators and teacher educators are discussed.
\end{abstract}

Keywords: professional burnout, perceived self-efficacy, EFL teachers

\section{Introduction}

Professional or job burnout is caused by long-term interpersonal stress in the working environment (Maslach, 1982). The condition develops when there is no match between occupational requirements and an employee's perceived capabilities (Brown, 2012; Maslach, Schaufeli, \& Leiter, 2001; Smith \& Bourke, 1992). According to Maslach (2015), burnout is "a psychological syndrome that develops in response to chronic emotional and interpersonal job stressors" (p. 1415). This phenomenon is so common among human service providers that it is often considered an index of mental and physical health (Jennett, Harris, \& Mesibov, 2003).

All too often, burnout can be traced back to externally driven factors such as long working hours or unpleasant working conditions (Lim, Kim, Kim, Yang, \& Lee, 2010), reduced levels of infrastructure and social support (KayEccles, 2012), increased levels of accountability (Dorman, 2003), and reduced management skills (Blase, 1984). Yet, it is equally important to consider individual and self-regulatory qualities that might yield important clues as to the possible genesis of the phenomenon. According to Alarcon, Eschelman, and Bowling (2009), perceived self-efficacy, i.e. beliefs in one's abilities, is one relevant factor. In this light, self-efficacy beliefs are held to shield employers against the adverse consequences of occupational stress (Brown, 2012).

Viewed from this perspective, the relationship between professional burnout and perceived self-efficacy finds great significance in the educational arena, particularly in relation to language teachers. An investigation into this relationship is particularly important for English as a foreign language (EFL) teachers who play a major role in today's globally interconnected world and amid the great demand for English language education in this world where English is the global lingua franca in many fields. As Jedynak (2011) states, the profession of a foreign language teacher can be over-stressed. EFL teachers constantly need to meet new challenges, obstacles, 


\section{ALI ROOHANI, MEHDI IRAVANI}

and difficulties in their teaching lives (Reeve \& Su, 2014). As Hong (2012) points out, state schools can become a tense site for EFL teachers with students who often lack enough motivation to learn English. They can gradually discover a conflict between their job expectations and the demands they actually experience; hence, they fail to meet their responsibilities properly. Thus, it is important to identify the culture-specific variables that can anticipate EFL teachers' burnout in different settings, such as public high schools where the pressure to satisfy professional requirements seems to be greater than private language schools (Rostami, Ghanizadeh, \& Ghapanchi, 2015).

Perceived self-efficacy, as an individual protective factor, might hold the key to the prediction, prevention, and understanding of professional burnout among language teachers. Previous research, using Bandura's (1994) concept of self-efficacy, has indictaed that teachers with a higher level of self-efficacy often see classroom demands and problems more as challenges than hindrances (Brouwers \& Tomic, 2000; Yang \& Farn, 2005). However, an examination of the related literature suggests that the relationship between self-efficacy and burnout has not received enough attention within the EFL context, particularly in public schools where EFL teachers face new challenges. The paucity of research in this area and the important role of EFL teachers in today's world where English is the dominant language in many areas could warrant further in-depth investigation into the possible relationship between EFL teachers' self-efficacy and their burnout. Investigating such affective and personality factors, as possible determinants of burnout, can contribute to preventing teacher burnout.

The antecedents of teacher burnout are commonly thought to have multifaceted factors (Chan, 2009). One group of burnout studies (e.g., Friedman \& Farber, 1992; Greenglass \& Burke, 1988) identify such antecedents as individual factors, which include demographic variables such as age, gender, and years of teaching experience. Among these variables, gender has been observed to be a likely factor both in the rate and the frequency of burnout symptoms among teachers (Klassen \& Chiu, 2010). However, other studies on gender and burnout (e.g., Lau, Yuen, \& Chan, 2005; Sari, 2004) did not focus on EFL teachers in public schools. Rather, they were concerned with the teachers whose majors were not teaching English in secondary or high schools. Inconsistencies and gaps can also be seen, depending on the occupation and culture-specific context of the studies (Purvanova \& Muros, 2010). It is thus assumed that gender-related studies on burnout among EFL teachers can enrich the related literature and shed some light on professional foreign language teachers' quality and expectations. In this light, this study was intended to investigate the possible relationship between the degree of perceived selfefficacy by Iranian EFL teachers and their level of professional burnout, and further examine whether gender could make a difference in the perceived components of burnout among Iranian EFL teachers.

\section{Teacher Burnout}

The term burnout found its way into the occupational literature in the early 1970s. Introduced by Freudenberger (1974), burnout was described as "a state of mental and physical exhaustion caused by one's professional life" (p. 160). In fact, burnout was considered a condition in which one is struck by constantly feeling stressed and, consequently, worn out due to unfulfilling working conditions.

Later on, however, Maslach (1982) offered a more scientific definition of the phenomenon, known as the state definition as the result of extensive research with her colleague, Mrs. Susan Jackson, on individuals working in

the human services sector. She posited a three-component approach to the concept of burnout, that is, emotional exhaustion, depersonalization, and reduced personal accomplishment. Accordingly, burnout was characterized as "a syndrome of emotional exhaustion, depersonalization, and reduced personal accomplishment that can occur among individuals who work with people in some capacity" (Maslach, et al., 1996, p. 4).

Emotional exhaustion is observed when a human services worker is bereft of any energy and motivation, represented by a sense of weariness (Maslach \& Jackson, 1986). Depersonalization (or cynicism) is the adoption of a cynic, indifferent, and impersonal attitude towards the service recipients (i.e., clients, patients, or students). The last component is reduced personal accomplishment. It represents the negative self-image one harbors about one's achievements, job performance, and ability to be successful at work or in life (Maslach, Schaufeli, \& Leiter, 2001).

The literature points extensively to the widespread existence of burnout among social and human services professionals (Skaalvik \& Skaalvik, 2010). Among these, schoolteachers are particularly more vulnerable than 
those working in other non-educational occupations, perhaps due to the effects of external social forces and internal critical agencies (Day \& Gu, 2010; Hanushek, 2007; McCarthy, Lambert, O’Donnell, \& Melendres, 2009; Van Tonder \& Williams, 2009). According to Hanushek (2007) and McCarthy et al. (2009), burnout among teachers is related to tiredness stemming from demands in the educational context (emotional exhaustion), a pessimistic viewpoint and lack of interest towards students (cynicism), and feelings of incompetency as a teacher (reduced personal accomplishment). Additionally, Van Tonder and Williams (2009) state that one of the main reasons for focusing on teachers in burnout studies is that burnout is more common in pedagogical settings than any other professional context. This is supported by Farber's (2000) estimation. He claims that 5 to 20 percent of American teachers suffer from burnout.

\section{Teacher Self-Efficacy}

The concept of self-efficacy is mainly attributed to Bandura's (1986) social cognitive theory. According to the theory, individuals are capable of human agency, that is, they intentionally pursue future courses of action. This assumes that what individuals believe about their own abilities will determine future behavior. The factors determining future behavior are behaviors, environmental influences, and internal individual factors such as affective, cognitive, and biological processes (Bandura, 1997). Bandura (1994) states that self-efficacy is "people's beliefs about their capabilities to produce designated levels of performance that exercise influence over events that affect their lives" (p. 71). When humans believe they can do something successfully, they enjoy self-efficacy (Woolfolk, 2004). The concept of perceived self-efficacy has also been described as "beliefs in one's capabilities to organize and execute the courses of action required producing given attainment" (Bandura, 1997, p. 3). It accounts for energy, effort, and persistence one is willing to invest in a task.

Self-efficacy is usually interpreted as a domain-specific concept. Teacher self-efficacy, often viewed as a futureoriented construct, is one such domain. It refers to "the teacher's belief in his or her capability to organize and execute courses of action required to successfully accomplishing a specific teaching task in a particular context" (Tschannen-Moran, Woolfolk Hoy, \& Hoy, 1998, p. 233). It is teachers' perceived competence in performing designated functions to achieve a set of educational goals, leading to students' learning facilitation and achievement (Skaalvik \& Skaalvik, 2010). The concept of self-efficacy, as applied in the area of education, has also inspired a number of researchers (e.g., Tschannen-Moran \& Woolfolk Hoy, 1998) to investigate how teachers' self-efficacy beliefs could influence their future behaviours and outcomes. According to social cognitive theory, advocated by Bandura (1994), teachers who do not expect success with their students are likely to invest less effort in the instruction, and are bound to give up more easily at the first hurdle. Therefore, the beliefs teachers have about their own pedagogic capabilities and knowledge, professional practice, and classroom management strategies could potentially impact their teaching productivity. In a similar vein, Collie, Shapka, and Perry (2012) emphasize that highly self-efficacious teachers firmly believe in their personal capacity to have a major impact on the educational processes, including students' learning. They are able to successfully meet school challenges, manifesting themselves mainly in issues such as students' disruptive behaviors, learning problems, communication with parents and colleagues, and school administration.

\section{The Self-Efficacy-Burnout Theoretical Link}

Burnout could have an adverse impact on professionals, particularly teachers. However, it is not judicious to claim that many teachers will suffer from this condition, and it is important to discover the factors that could cushion its negative effects. Social cognitive theory postulates that self-efficacy could be an aid to recovery from job strain (Unsworth \& Mason, 2012) and a facilitator of adaptation to change in the organization (Bandura, 1994, 1995, 1997). Efficaciousness, or self-efficacy beliefs, consciously or unconsciously, can affect one's choices, efforts, persistence, and emotions in the face of adversity. Extending this to educational contexts, teachers who enjoy high self-efficacy are more confident in their capabilities to get the desired results. According to Bandura (1997), efficaciousness, consciously or unconsciously, can affect one's choices, efforts, persistence, and emotions in the face of adversity. In educational contexts, self-efficacy beliefs are believed to act between knowledge and behavior. Self-efficacy beliefs influence behavior through four mediating processes, that is, cognitive, affective, motivational, and selective processes. These mediating processes can greatly affect the performance of teachers in schools and negatively affect thought patterns, self-regulation of affective states, the selection of activities, and regulations of motivation in teachers who harbor self-doubts and inefficacy (Evers, Brouwers, \& Tomic, 2002), which can be a mediator of burnout (Bandura, 1997). 
More recently, as Brown (2012) states, foreign/second language (L2) researchers have begun to show interest in teacher self-efficacy and review its relationship with other affective variables, including those related to the dimensions of burnout. The common thread among their arguments is that perceived self-efficacy beliefs may be negatively correlated with feelings of being overextended and losing an emotional or cognitive involvement with work. However, it can be positively related to feelings of competence and productivity at work (Hong, 2012).

In a systematic review, Brown (2012) claims an association between self-efficacy and burnout among teachers, with the strongest association between self-efficacy with depersonalization and emotional exhaustion. Brouwers and Tomic (2000) have also reported that self-efficacy has a longitudinal effect on depersonalization and a synchronous impact on personal accomplishment, whereas the direction can be reverse for emotional exhaustion. In a similar vein, Aloe, Amo, and Shanahan (2014) have suggested that higher levels of self-efficacy in classroom management make teachers less vulnerable to feelings of burnout. Betoret (2009) also concludes that job stressors, stemming from low instructional self-efficacy, can be a major factor in burnout.

Chwalisz, Altmaier, and Russell (1992) related self-efficacy beliefs to the realm of dealing with the most stressful situations that teachers experienced at their job. In a correlational study, they examined the relationships among causal attributions, self-efficacy cognitions, and coping through data collected from 316 public school teachers in the Netherlands. They reported that teacher burnout could be moderately linked to teacher self-efficacy. They also found that teachers who were unsure about their ability to effectively cope with stressful events showed a higher level of burnout than their colleagues who demonstrated more self-confidence in this area. Evers, Brouwers, and Tomic (2002) also studied burnout among 490 teachers who were employed in the upper grades of schools of higher general secondary education in the Netherlands. Similarly, the results indicated that teachers' self-efficacy beliefs were associated with their burnout level in a moderate way. However, Skaalvik and Skaalvik (2007) reported a strong relationship between teacher self-efficacy and teacher burnout among elementary Norwegian teachers. It seems there is no clear consensus regarding the level of the relationship between teacher self-efficacy and teacher burnout in different contexts.

Despite the potential theoretical link between the teacher burnout and self-efficacy, more investigations on the issue, especially in different educational systems, are in order. As Perrewé et al. (2002) state, these concepts could go well beyond cultural and national boundaries to (in)validate the theoretical foundations and previous findings. Perhaps, the different characteristics of educational systems can result in different conceptualizations and findings. Moreover, no systematic studies have explored the association between teacher burnout and selfefficacy among EFL teachers in the context of Iranian public high schools both in a quantitative and qualitative manner. The existing literature has provided some insight for the association between teacher burnout and selfefficacy. However, the prior studies were conducted in other contexts such as in the Turkish context (e.g., Ozkara, 2019) or in private language institutes (e.g., Motallebzadeh, Ashraf, \& Tabatabaee-Yazdi, 2014). Additionally, an investigation into the association between teacher burnout and self-efficacy with a mixed-methods approach can be more conducive for learning about culture-specific factors involved in burnout experience among EFL teachers in the context of Iranian public schools.

Moreover, evidence suggests that the demographic variable of gender is a likely candidate in burnout research (Biron \& Link, 2014). However, controversies surround the role played by gender in the qualitative and quantitative development of the burnout phenomenon (Schwarzer \& Hallum, 2008). Some research studies point to higher degrees of burnout among females (e.g., Maslach, 1982; Poulin \& Walter, 1993). For instance, Sari (2004) reported higher levels of emotional exhaustion and personal accomplishment among female teachers in Turkish high schools. In contrast, Küçüksüleymanoğlu (2011) concluded that male teachers in special education schools in Turkey showed more symptoms of emotional exhaustion and depersonalization, with no significant difference for personal accomplishment. In a cross-cultural research study, Schwarzer and Hallum (2008) found no major gender effect for burnout components except for depersonalization for male Syrian and German teachers. In the EFL context, Motallebzadeh et al. (2014) and Mardani, Baghelani, and Azizi (2015) came up with different mixed results on the role of gender in teacher burnout. Additionally, Mede (2009) found gender to be an insignificant factor in the burnout experience. Given the inconclusiveness surrounding the role played by gender, and considering the fact that females constitute a large portion of EFL teachers in Iran, particularly in public high schools, understanding gender-related differences among teachers in the EFL context of Iran, where demands for expanding new knowledge and sharing it with the world outside are rapidly increasing, it is necessary to investigate the possible role of gender in the burnout experience. 
The study, therefore, sought answers to the following questions:

1. Is there any significant relationship between perceived self-efficacy and professional burnout among Iranian EFL teachers?

2. Is there any significant difference between male and female Iranian EFL teachers in professional burnout?

3. Does the qualitative data help explain the results from the initial quantitative phase of the study?

Accordingly, the following null hypotheses were formulated to address the two first research questions:

$\mathrm{H}_{01}$ : There is no statistically significant relationship between perceived self-efficacy and professional burnout among Iranian EFL teachers.

$\mathrm{H}_{02}$ : There is no statistically significant difference between male and female Iranian EFL teachers regarding professional burnout.

\section{Method}

\section{Participants}

The participants were $80 \mathrm{EFL}$ teachers from Isfahan, Iran. They were all native speakers of Persian. The participants consisted of 44 males and 36 females, working full time in nine public high schools. Their teaching experience ranged from 12 to 25 years. The selection of the research site was driven by the assumption that teachers working in secondary education, particularly in public schools, are vulnerable to burnout risks (Otero López et al., 2008). The selection was based on convenience sampling and the sample size was considered satisfactory for the purpose of the study. The participants' age ranged from 35 to 56 . The teachers had majored in Teaching of English as a Foreign Language (TEFL, $n=36)$, English Translation $(n=20)$, English Literature $(n$ $=14)$, and Linguistics $(n=10)$. They had bachelor's $(n=49)$ and master's $(n=31)$ degrees.

\section{Assessments and Measures}

Two questionnaires were used to collect the data on the professional burnout and perceived self-efficacy from the participants. The first was the Maslach Burnout Inventory-Educator's Survey (MBI-ES) (Maslach \& Jackson, 1986). The inventory includes 22 items with a seven-point scale ranging from 0 (never) to 6 (every day) with higher scores indicating a higher frequency of occurrence of feelings described for each item. The inventory captures the three dimensions of burnout, namely, emotional exhaustion (EE) (e.g., "I feel emotionally drained from my work"), depersonalization (DP) (e.g., “I don't really care what happens to some students"), and (reduced) efficacy or personal accomplishment (PA) (e.g. "I have accomplished many worthwhile things in this job”). The participants were allotted 25 minutes to complete the questionnaire. Several researchers (e.g., Akbari, Ghafar Samar, Kiani, \& Eghtesadi, 2011; Byrne, 1993; Schwarzer, Schmitz, \& Tang, 2000) have established the validity of the MBI-ES. Early on, Maslach and Jackson (1986) demonstrated that the three dimensions had good psychometric properties. They confirmed the convergent validity of the questionnaire by correlating MBI-ES scores with: 1) indexes of various outcomes postulated to be associated with burnout, such as job dissatisfaction; 2) job characteristics expected to contribute to burnout, such as heavy workloads; and 3) behavioral ratings by those knowing the individuals (e.g., colleagues). Kokkinos (2007) also confirmed the three factor structures of burnout employing exploratory and confirmatory factor analysis. Regarding the internal consistency of the scale, Cronbach's alpha coefficients for all the subscales were above .70 in the current study, with EE $(\alpha=.78)$, $\mathrm{DP}(\alpha=.74)$, and PA $(\alpha=.83)$.

The second questionnaire was a modified version of Teacher Sense of Efficacy Scale (TSES, Tschannen-Moran \& Woolfolk Hoy, 2001), developed and validated by Eslami and Fatahi (2008) in the context of Iran. Recently, using the Rasch model, Chang and Engelhard (2016) reconfirmed the validity of the original questionnaire with data from 554 teachers in a US Midwestern state. The inventory includes 12 items with a five-point Likert scale, ranging from 1 (not at all) to 5 (a great deal). It has three subscales: (a) efficacy for instructional strategies (IS, $\alpha=.81$ in the current study) (e.g., "To what extent can you provide an explanation or example when students are confused?"), (b) efficacy for classroom management (CM, $\alpha=.83$ in the current study) (e.g., "How much can you do to control disruptive behavior in the classroom?"), and (c) efficacy for student engagement (SE, $\alpha=.80$ in the current study) (e.g., "How much can you do to motivate students who show low interest in school work?"). The participants were allotted 15 minutes to complete the questionnaire. Meanwhile, the participants had to 
provide their demographic information, such as gender, years of teaching experience, highest academic degree, and academic major at the beginning of the two questionnaires employed in the study.

A semi-structured interview was carried out as a follow-up step to the quantitative phase for the qualitative part of the study. Several questions were carefully prepared to help contextualize and explain the quantitative data. The questions were reviewed by five experienced principals working in other school districts to provide feedback regarding their clarity, appropriateness, and ability to elicit relevant information. The questions included yes/ no and open-ended questions (see Appendix). Moreover, if necessary, more probing questions were raised.

\section{Procedure}

To gather the data, the two questionnaires were distributed among the participants who were asked to fill them out in their schools. It took about one weak to have all the copies collected. The data were analyzed for descriptive and inferential statistics using SPSS.

Additionally, in order to invest more confidence in the validity of the scores and to get a more comprehensive understanding of the possible relationship between the participants' level of self-efficacy and burnout, 15 teachers sat to be interviewed. They consisted of volunteer teachers who were selected from the sample in the quantitative phase. They included the teachers with both high and low levels of self-efficacy. They comprised eight teachers with high scores on the TSES questionnaire and seven teachers with low scores on the TSES questionnaire. The interviews were conducted face-to-face in their schools, each lasting about 25 minutes. The respondents were assured that their personal information would be confidential. All the interviews were digitally recorded and transcribed. Afterwards, following Mackey and Gass (2005), the transcripts were read several times to identify salient features and organize the raw data into categories for further analysis. They were coded and themes were identified by the present researchers, who moved back and forth between the gathered data and codes to identify the emerging themes. To ensure the credibility of the interview data, peer-debriefing and member-checking were utilized. For the member-checking, the participants were invited to review the transcripts and emerging themes to assess the accuracy of the interpretations. The peer-debriefing involved an external check by a PhD student, an expert in qualitative data analysis, who was provided with the data and our interpretations to make sure the interpretation of data was credible.

\section{Quantitative Phase}

\section{Results}

Table 1 reports the descriptive statistics of the three dimensions of the MBI-ES, namely, emotional exhaustion, depersonalization, and personal accomplishment.

Table 1

Descriptive Statistics of the MBI-ES Dimensions

\begin{tabular}{lccccrrrr}
\hline Dimension & $\begin{array}{c}\text { N of } \\
\text { Items }\end{array}$ & Min & Max & $\begin{array}{c}\text { Total } \\
\text { Mean }\end{array}$ & SD & $\begin{array}{c}\text { Scale } \\
\text { Mean }\end{array}$ & SSkewness & Kurtosis \\
\hline EE & 9 & 14 & 35 & 25.98 & 6.15 & 2.89 & -.15 \\
DP & 5 & 8 & 19 & 13.13 & 2.92 & 2.63 & -1.25 \\
PA & 8 & 11 & 31 & 20.68 & 7.49 & 2.59 & .26 & -1.76 \\
\hline
\end{tabular}

Note . $\mathrm{EE}=$ Emotional Exhaustion $; \mathrm{DP}=$ Depersonalization $; \mathrm{PA}=$ Personal Accomplishment

According to guidelines suggested by Maslach, Jackson, and Leiter (1996), scores on the three dimensions of MBI-ES can be low, moderate, or high if the mean scores fall in the lower, middle, and upper third categories, respectively. Following Maslach et al.'s (1999) guidelines, the mean score for EE was considered moderate to high as it fell in the middle third range of score category (17-26). The mean score for DP fell in the upper third $(\geqslant 13)$, which was high. The mean score for PA also fell in the upper third $(\leqslant 31)$, indicating a low sense of PA and high level of reduced PA. In sum, the EFL teachers reported a relatively high level of burnout, in general.

Table 2 reports the descriptive statistics of three dimensions of the TSES, namely, student engagement, classroom management, and instructional strategies. 
Table 2

Descriptive Statistics of the TSES Dimensions

\begin{tabular}{lccccccccc}
\hline Dimesnsion & $\begin{array}{c}\text { N of } \\
\text { Items }\end{array}$ & Min & Max & $\begin{array}{c}\text { Total } \\
\text { Mean }\end{array}$ & SD & $\begin{array}{c}\text { Scale } \\
\text { mean }\end{array}$ & Skewness & Kurtosis \\
\hline SE & 4 & 5 & 20 & 11.91 & 3.79 & 2.98 & .167 & -.94 \\
CM & 4 & 4 & 20 & 11.96 & 3.62 & 2.99 & .166 & -.66 \\
IS & 4 & 5 & 20 & 13.18 & 3.61 & 3.29 & .026 & -.08 \\
Total & 12 & 15 & 58 & 37.05 & 10.54 & 3.09 & .025 & -.76 \\
\hline
\end{tabular}

Note. $\mathrm{SE}=$ Student Engagement $; \mathrm{CM}=$ Classroom Management; IS = Instructional Strategies

As observed in Table 2, the total self-efficacy mean was 37.05. Given that the possible range of scores for selfefficacy was 12-60 with 12 Likert-type items each with five options, the scale mean was 3.09, which was obtained through dividing the mean score by the number of items. This number was close to the third option (Some Degree) on 5-point Likert items. This result does not reflect a very high level of perceived self-efficacy among the teachers. This is especially the case for the subcomponents SE (2.98) and CM (2.99).

To examine the first null hypothesis stating that there is no statistically significant relationship between perceived self-efficacy and professional burnout among Iranian EFL teachers, a Pearson's product correlation was run between these two variables. The results are summarized in Table 3.

Table 3

Correlations between Teacher Self-Efficacy and Burnout Dimensions

\begin{tabular}{|c|c|c|c|}
\hline & $\mathrm{EE}$ & DP & PA \\
\hline Teacher Self-Efficacy & $\begin{array}{l}-.66^{\text {*** }} \\
\left(r^{2}=.44\right) \quad\left(r^{2}=.32\right)\end{array}$ & $\begin{array}{l}-.57^{\text {w*x }} \\
\left(\mathrm{r}^{2}=.62\right)\end{array}$ & $.79^{* * *}$ \\
\hline
\end{tabular}

Note. ${ }^{* *} p<.01$

As displayed in Table 3, there is a statistically significant and strong negative correlation $(p=.000)$ between EE and teacher self-efficacy, with higher levels of teacher self-efficacy associated with lower levels of EE. Additionally, following Larson-Hall's (2010) guidelines, there is a moderate to large negative correlation between DP and teacher self-efficacy, with higher levels of teacher self-efficacy significantly associated with lower levels of DP. As for PA, the correlation was also statistically significant with a large effect size, but in a positive direction $(p$ $=.000)$. As the teachers' self-efficacy increased, so did their PA.

Moreover, to address the second null hypothesis stating that there is no statistically significant difference between male and female Iranian EFL teachers regarding professional burnout, independent $t$-tests were run for each burnout dimension (see Table 4).

Table 4

Independent t-Tests for MBI-ES Dimension Scores for Both Males and Females

\begin{tabular}{|c|c|c|c|c|c|c|c|c|c|c|}
\hline \multirow[b]{3}{*}{ Dimensions } & \multicolumn{6}{|c|}{ Groups } & \multirow[b]{3}{*}{$\mathbf{t}$} & \multirow[b]{3}{*}{ df } & \multirow[b]{3}{*}{ Sig } & \multirow[b]{3}{*}{$\begin{array}{c}\text { Eta } \\
\text { Squared }\end{array}$} \\
\hline & \multicolumn{3}{|c|}{ Male } & \multicolumn{3}{|c|}{ Female } & & & & \\
\hline & $\mathbf{M}$ & SD & $\mathbf{n}$ & $\mathbf{M}$ & SD & $\mathbf{n}$ & & & & \\
\hline $\mathrm{EE}$ & 30.75 & 4.25 & 44 & 21.20 & 3.52 & 36 & 11.03 & 78 & .000 & .43 \\
\hline DP & 15.35 & 1.87 & 44 & 10.90 & 1.91 & 36 & 10.57 & 78 & .000 & .41 \\
\hline PA & 16.10 & 4.68 & 44 & 25.25 & 6.98 & 36 & -6.89 & 78 & .000 & .30 \\
\hline
\end{tabular}

As demonstrated in Table 4, there were statistically significant differences between the male and female teachers in all three burnout dimensions. The results indicate that males had significantly higher scores for $\mathrm{EE}(p=.000)$, with a medium effect size. The female teachers, however, received significantly higher scores for PA $(p=.000)$, with a medium effect size. 


\section{Qualitative Phase}

The present study employed a sequential mixed-method design to answer the third research question. The collection and analysis of data from the quantitative survey was followed by the semi-structured interviews, which helped as a secondary source to validate the quantitative results (Creswell, 2009). As with the quantitative part, the qualitative analysis focused on the teacher burnout and perceived self-efficacy variables. Coding and analysis of the interview data generated themes or concepts related to these variables, which are summarized in Table 6 and explained below.

Table 6

Emergent Themes from the Interview Data

\begin{tabular}{lc}
\hline \multicolumn{1}{c}{ Themes } & Number of Teachers \\
\hline Mental fatigue & 8 \\
\hline Contact avoidance & 6 \\
\hline Stress & 7 \\
\hline
\end{tabular}

\section{Mental fatigue}

The first theme that emerged from the interviewees' responses was mental fatigue. The low self-efficacious teacher participants felt more mentally fatigued. They were unable to recover their energy after a hard day's work at school. Almost all of them reported enduring fatigue. For example, one of the male EFL teachers with 20 years of teaching experience in several public schools commented, "at the end of the day, I feel so tired ..., er, so motionless when I get up in the morning, facing a new day. My wife becomes worried about my health." As to the self-efficacy side of the story, being a low self-efficacious teacher, he also said:

As I speak or ... teach in the class, I'm repeatedly interrupted by noisy and mischievous students and, ... er ...well ..., don't know how to restore order to the class. I will be really at a loss for words and will have no idea of how to react properly...I am tired.

However, the teachers with a higher level of self-efficacy, pointed to their energy when dealing with the students and their problems. One highly energetic female teacher said, "My energy and activity can keep me going the whole day...I like my job." Although some of the self-efficacious teachers reported transient feelings of tiredness and frustration, they were relieved by subsequent routine recovery periods. Therefore, these transient experiences of fatigue were not regarded as representative of burnout themes.

\section{Contact avoidance}

Another theme was related to avoiding too much personal and interpersonal relationship with EFL students. The low self-efficacious teachers were inclined to keep a distance from their students, especially outside the classroom. They reported keeping a low profile most of the time. Their main reason seemed to be harboring a deep resentment of disruptive students, violence, discipline problems (e.g., shouting in the class), and students' inattention and lack of interest in learning. One male teacher with a bachelor's degree in the Teaching of English said:

I am really put off at the sight of some of my students. They don't know how to behave themselves. That's intolerable .... They're ... awful. I wonder why just .... why they, ... er, waste their time here. It is not good to be a teacher here.

Another male teacher participant explained, “I don't really care if my students understand the material or not, I do not want to see them in the office at all." On the other hand, teachers with high levels of self-efficacy reported a tendency to have more contact with their students and highlighted the need to build mutual trust in and out of the classroom. One of the female interviewees with 16 years of teaching experience explained, "I love my job and students; having close relationships with students could be more of a help. It can change their negative attitudes." In sum, the majority of high self-efficacious teachers strongly believed in the importance of paying undivided attention to the interactional and interpersonal relationships with their students. 


\section{Stress}

The last emerging theme was related to the teachers' stress and anxiety in their job due to a lack of skills, great expectation and challenges, and long hours spent in the classroom. Stress manifested itself when the low selfefficacious teachers were bereft of the necessary skills and resources to deal with the diverse demands and expectations on the part of students and cope with unexpected challenges in the schools. One male teacher with a low level of efficacy, who had 12 years of teaching experience, explained, "Teaching English is a stressful job and all eyes are fixed on you. It puts pressure on you and you cannot motivate the students enough." Another male teacher disclosed:

When a student raises his hand to ask a question, I become so keyed up. I wonder if I'll be on the right path. It's very very, er, dreadful. The problem gets worse when a student tries to pull your leg with a grammatical point or word you don't have the foggiest idea about.

Another source of stress was related to the expectations on the part of visiting parents. A young female teacher, who was thinking about changing her job, reported, “... the problem is that if anything goes wrong, everyone will hold the teacher responsible." Another dissatisfied male teacher claimed, "If a student gets a poor mark on an exam, his or her parent will visit the school and hold the researcher responsible."

These remarks, however, were in sharp contrast with the feelings reported by teachers with higher levels of self-efficacy. The teachers were found to be less affected by feelings of chronic stress and anxiety. One of them explained:

I like the challenge in my job so much and I like different students attending my class with different background knowledge ..., the variety in the job is very satisfying.

In sum, the teachers who were rated as high in self-efficacy were judged to suffer less from the symptoms of professional burnout while those who were ranked as low in self-efficacy seemed to show more signs of job burnout.

\section{Discussion}

In response to some suggestions in the literature for greater insight into the interaction between personal attributes that could play a part in teacher burnout, the present study delved into teacher burnout and selfefficacy and their relationship in the EFL high school context in Iran. Based on the descriptive statistics, the high school EFL teachers in the study displayed a risk profile on burnout when their scores were compared with the guidelines offered by Maslach et al. (1996). Considering the moderate-to-high level of EE, high level of DP, and reduced PA, one can infer that the participants did not enjoy a satisfactory level of individual achievement and self-efficacy. The descriptive statistics on the self-efficacy measure lent support to this line of interpretation. The self-efficacy scores, in general, did not depict a high sense of perceived self-efficacy among the EFL teachers. This was also observed with respect to the self-efficacy subcomponents, too. These results indicate that the high school English teachers did not feel very competent doing their job and many had feelings of burnout in their high school teaching jobs. As Friedman and Farber (1992) argued, teachers with a high level of inefficacy and a low sense of classroom efficacy feel stressed and pessimistic about their work and students' ability to improve.

Furthermore, the correlational results provided evidence to reject the first null hypothesis of the study and indicated a meaningful relationship between the teachers' self-efficacy and the three dimensions of job burnout in the EFL context of Iran. The results from correlational analysis revealed that the EFL high school teachers' depersonalization and emotional exhaustion had negative and significant relationships with their self-efficacy, that is, the beliefs they had about their own abilities to organize and implement the courses of action in teaching English. As Schwarzer and Hallum (2008) pointed out, the self-efficacy construct implies a kind of protective tool when coping with unfavorable working conditions. Enjoying a strong sense of belief in one's occupational capabilities and the self-confidence to effectively deal with work challenges will boost the motivation to engage in strategies of coping. This being the case, the highly self-efficacious teacher participants interpret 


\section{ALI ROOHANI, MEHDI IRAVANI}

their daily instructional challenges in the classroom as being less menacing than teachers who harbored selfdoubts about their job performance and achievement. It is very likely that successful adaptation to stressful expectations and demands in the EFL classroom would stop or delay job burnout. Therefore, self-efficacy can make a difference in how EFL teachers think, feel, and perform in the classroom. Furthermore, the relatively high negative correlations between depersonalization and emotional exhaustion with teacher self-efficacy, on the one hand, and the large positive correlation between personal accomplishment and teacher self-efficacy, on the other hand, support the findings reported by Mardani et al. (2015) and Motallebzadeh et al. (2014) who came up with the reverse correlations between teacher burnout and self-efficacy variables among English language teachers in different contexts. Specifically, they found that instructional efficacy was the most important factor in predicting emotional exhaustion, depersonalization, and personal accomplishment. Additionally, the results of the study by Ozkara (2019), conducted among Turkish EFL state teachers, count as a piece of corroborative evidence for this kind of relationship between self-efficacy and burnout components. More likely, the significant role of self-efficacy in burnout experience cuts across EFL boundaries and different geographical and cultural contexts. This is particularly evident in the findings of the study by Skaalvik and Skaalvik (2007), who reported that a low level of self-efficacy among Norwegian elementary teachers could increase the risk of occupational stress, which might, in turn, increase the level of emotional exhaustion and depersonalization. Therefore, the antecedents underlying teacher burnout and the mitigating effect of self-efficacy on this phenomenon seem to be not confined to a specific educational and cultural milieu.

The main themes of mental fatigue, contact avoidance, and stress emerged from the in-depth qualitative analysis also demonstrated that EFL teachers who were rated as low in self-efficacy were more vulnerable to the symptoms of professional burnout. According to the data, the first dominant symptom in the majority of the EFL teachers with low self-efficacy and who were suffering from temporal or chronic burnout was the feeling of mental fatigue. Being unable to successfully overcome some of the daily obstacles in teaching English in a high school and dealing with their students' noncompliant behavior in the classroom, the low self-efficacious teachers were gradually overcome by feelings of lassitude and decided to change their job. As Hong (2012) points out, such a situation over time drains the teacher's energy and interest to the point of deciding to quit the job. The theme of contact avoidance, which was mostly observed in the low self-efficacious male teachers, can also be interpreted as the inability of such teachers to develop effective communicative, instructional, and class management strategies for confronting new challenges in foreign language teaching. More likely, those participants who were identified as suffering from the depersonalization dimension had resorted to a kind of professional seclusion. This relational avoidance had, in turn, resulted in their adoption of an air of indifference towards their professional improvement and their students' insignificant L2 achievement. The theme of stress was also related to such issues as the students' diverse needs and expectations in L2 learning, incongruence between the teachers' expectations and job demands, class management problems, as well as great expectations on the part of other stakeholders. The high self-efficacious teachers, particularly the female ones, were reportedly less affected by this negative emotional quality. These EFL teachers, perhaps, were equipped with internal coping tools and resources like resilience to better manage stress in their profession over the long term.

Furthermore, considering the role of gender in EFL teachers' burnout, the results showed that gender, to some extent, could be considered a modifying variable in explaining the difference in burnout experiences among the EFL teachers. The male teachers reported perceived symptoms of emotional exhaustion and depersonalization more frequently than the female teachers. As a possible reason, it can be argued that a sense of social responsibility and occupational commitment was stronger among the female EFL teachers, who had more tendencies to socialize at school, build good relations with their students or colleagues, and use their coping strategies in the face of problems. As Maslach and Jackson (1985) asserted, the female role in the workplace is often characterized with a nurturing and caring attitude when dealing with different people and their problems. This can possibly protect female EFL high school teachers against the negative consequences of job burnout. However, unfavorable job-related factors such as low payment might contribute to higher burnout levels among male EFL teachers in the public high school context in Iran. The above results on gender differences support the results of studies by Küçüksüleymanoğlu (2011) and Motallebzadeh et al. (2014) who reported that female teachers would not be affected as much as male teachers by the unpleasant conditions of the teaching profession. Küçüksüleymanoğlu (2011) found out that male teachers in special education schools in Turkey felt more emotionally exhausted than female teachers. Motallebzadeh et al. (2014) also reported that male teachers' level of burnout was significantly higher than that of the female teachers in private language institutes in Khorasan Razvi, Iran. Along the same lines, while exploring the cross-sectional associations between teacher 
burnout and several putative precursors, Schwarzer and Hallum (2008) found that male German and Syrian teachers experienced more depersonalization than female German and Syrian teachers. Nonetheless, these findings are not consistent with the findings of the studies by Mardani et al. (2015), who concluded that EFL female teachers experienced more burnout symptoms than male teachers, and Mede (2009), who did not find gender as a significant predictive factor in the three burnout dimensions among Turkish EFL teachers. It seems that the context of teaching and educational environment of foreign language teaching in schools can pose different types of challenges for female and male teachers, leading to mixed gender-related differences in reported burnout. Thus, the role of the gender effect in burnout studies should be treated with caution.

\section{Conclusion}

What this research study has brought home is the importance of perceived self-efficacy as an internal protective factor against burnout in pedagogical settings. The present study has confirmed the significant correlation between teacher self-efficacy and professional teacher burnout, a phenomenon affecting both teacher turnover rates and student outcomes. The findings revealed that higher burnout levels correlated meaningfully with lower levels of self-efficacy among EFL teachers. Additionally, female teachers demonstrated lower burnout levels than the male ones, highlighting the modifying function of the gender variable in burnout studies. The follow-up semi-structured interviews also supported these quantitative findings on the negative association between teacher self-efficacy and professional teacher burnout. The three main themes of mental fatigue, contact avoidance, and stress emerged in explaining the burnout experience of EFL teachers.

The negative consequences of burnout call for teacher educators in the EFL context to understand the conditions leading to this phenomenon and the factors fostering teacher self-efficacy. After all, if EFL teachers hope to function as a torch for EFL students and provide them with opportunities for personal growth and the motivation to learn, as the results suggest, they need to develop persistence and resilience when they face pedagogical challenges in teaching a foreign language. Therefore, L2 teacher educators should seize the opportunity to inculcate these essential qualities in EFL teachers. The relationship between teacher self-efficacy and professional teacher burnout also implies that L2 administrators should develop programs to train teachers with strong positive beliefs in their capabilities early on in their L2 teaching career, and set up a congenial environment at schools to boost self-efficacy among EFL teachers.

At the same time, L2 teachers should be assisted in expanding their skills for managing the feelings of incompetency, stress, and the resulting negative effects in L2 classes. The findings highlight the important role of L2 school administrators in discussing the antecedents of teacher burnout and providing a flexible and supportive environment to reduce EFL teachers' sense of exhaustion and stress. Additionally, L2 educators are recommended to pay attention to teacher self-efficacy as a pedagogical quality when recruiting foreign language teachers.

Last but not least, the findings should be interpreted in light of some limitations. First, some results were based on self-reported data. As Gay, Mills, and Airasian (2009) point out, participants in a survey might select the responses that are more desirable even if they do not actually believe them. Thus, other types of data collection procedures such as diaries, as recommend by Clarkson and Hodgkinson (2007), can be employed to make stronger generalization about the association between self-efficacy and professional burnout among EFL teachers. Future L2 burnout research might also benefit from data provided by students on EFL teachers' burnout experience and self-efficacy. This can be complementary to the primary data, and hence reduce any possible bias. Second, the current study used semi-structured interviews for the data triangulation; however, the codes that evolved from the qualitative interview data were limited to some EFL teachers who presented their reflections according to their personal views. Other codes could, therefore, be generated by conducting interviews at a different time with other foreign language teachers. Third, the degree of motivation by EFL students might have affected the teachers' burnout levels. As research (e.g., Anderson \& Iwanicki, 1984; Roohani \& Dayeri, 2019) suggests, student motivation could be a contributing factor in the burnout experience. Therefore, future research can take student motivation into consideration in burnout studies. Fourth, the present study did not include a control group of schoolteachers in other disciplines in dealing with the relationship between selfefficacy and the burnout experience among language teachers. Future research, however, can include a control 


\section{ALI ROOHANI, MEHDI IRAVANI}

group of schoolteachers, such as mathematics teachers, who may suffer from similar challenges when they are engaged in teaching (Cui et al., 2018). In this way, one might gain more insight into the phenomenon of burnout and its possible cross-disciplinary differences. Fifth, this study was conducted with a relatively small sample of EFL teachers in Iran. Future research can be carried out with a larger sample and other types of sampling because research shows that a larger sample is more representative of the population (Robson, 1993). Finally, the findings, particularly those on the gender effect, must be treated with caution if they are generalized to EFL teachers in the context of decentralized educational systems like private language institutes where the context is different from a centralized educational system like public high schools in Iran. Future research can also replicate the same study among EFL teachers in other contexts.

\section{References}

Akbari, R., Ghafar Samar, R., Kiani, Gh., \& Eghtesadi, A. (2011). Factorial validity and psychometric properties of Maslach burnout inventory-the Persian. Knowledge and Health, 6(3), 1-8.

Alarcon, G., Eschleman, K. J., \& Bowing, N. A. (2009). Relationship between personality variables and burnout: A meta-analysis. Work \& Stress, 23, 244-263.https://doi.org/10.1080/02678370903282600

Aloe, A. M., Amo, L. C., \& Shanahan, M. E. (2014). Classroom management self-efficacy and burnout: A multivariate meta-analysis. Educational Psychology Review, 26(1), 101-126. https://doi.org/10.17323/jle.2019. v5.i410.1007/s10648-013-9244-0

Anderson, B. G., \& Iwanicki, E. F. (1984). Teacher motivation and its relationship to burnout. Educational Administration Quarterly, 20, 109-132. https://doi.org/10.1177/0013161X84020002007

Bandura, A. (1994). Self-efficacy. In V. S. Ramachandran (Ed.), Encyclopedia of human behavior (vol. 4, pp. 71-81). Academic Press.

Bandura, A. (1995). Self-efficacy in changing societies. Cambridge University Press.

Bandura, A. (1997). Self-efficacy: The exercise of control. Freeman.

Betoret, F. D. (2009). Self-efficacy, school resources, job stressors, and burnout among Spanish primary and secondary school teachers: A structural equation approach. Educational Psychology, 29(1), 45-68. https://doi. org/10.1080/01443410802459234

Biron, M., \& Link, S. (2014). Stress, appraisal, and work routine in wartime: Do men and women differ? Anxiety, Stress, \& Coping, 27, 229-240. https://doi.org/10.1080/10615806.2013.836506

Blase, J. J. (1984). School principals and teacher stress: A qualitative analysis. National Forum of Educational Administration and Supervision, 1(2), 35-43.

Brouwers, A., \& Tomic, W.(2000). A longitudinal study of teacher burnout and perceived self-efficacy in classroom management. Teaching and Teacher Education, 16, 239-253. https://doi.org/10.1016/S0742-051X(99)00057-8

Brown, C. G. (2012). A systematic review of the relationship between self-efficacy and burnout in teachers. Educational \& Child Psychology, 29, 47-63.

Burke, R. J., \& Richardsen, A. M. (1996). Stress, burnout, and health. In C. L. Cooper (Eds.), Handbook of stress, medicine, and health (pp. 101-117). CRC Press.

Byrne, B. M. (1993). The Maslach Burnout Inventory: Testing for factorial validity and invariance across elementary, intermediate, and secondary teachers. Journal of Occupational and Organizational Psychology, 66, 197-212. https://doi.org/10.1111/j.2044-8325.1993.tb00532.x

Chan, D. W. (2008). Teacher self-efficacy and successful intelligence among Chinese secondary school teachers in Hong Kong. Educational Psychology, 28(7), 735-746. https://doi.org/10..1080/01443410802259246

Chan, M. (2009). An appraisal perspective of teacher burnout: Examining the emotional work of teachers. Educational Psychology Review, 21, 193-218. https://doi.org/10.1007/s10648-009-9106-y

Chang, M. L., \& Engelhard, G. (2016). Examining the teachers' sense of efficacy scale at the item level with Rasch measurement model. Journal of Psychoeducational Assessment, 34(2), 177-191. https://doi. org/10.1177/0734282915593835

Chwalisz, K., Altmaier, E. M., \& Russell, D. W. (1992). Causal attributions, self-efficacy cognitions, and coping with stress. Journal of Social and Clinical Psychology, 11, 377-400. https://doi.org/10.1521/jscp.1992.11.4.377

Clarkson, G. P., \& Hodgkinson, G. P. (2007). What can occupational stress diaries achieve that questionnaires can't? Personnel Review, 36(5), 684-700. https://doi.org/10.1108/00483480710773990

Collie, R. J., Shapka, J. D., \& Perry, N. E. (2012). School climate and social-emotional learning: Predicting teacher stress, job satisfaction, and teaching efficacy. Journal of Educational Psychology, 104(4), 1189-1204. 1204. 
https://doi.org/10.17323/jle.2019.v5.i4 10.1037/a0029356

Coulter, M. A., \& Abney, P. C. (2009). A study of burnout in international and country of origin teachers. International Review of Education, 55, 105-121.

Creswell, J. W. (2009). Research design: Qualitative, quantitative, and mixed methods approaches. Sage.

Cui, Q., Chao, Q., Han, J., Zhang, X., Ren, Y., \& Shi, J. (2018). Job stress, burnout and the relationship among the science and mathematics teachers in basic education schools. Eurasia Journal of Mathematics, Science and Technology Education, 14(7), 3235-44. https://doi.org/10.29333/ejmste/85957

Day, C., \& Gu, Q. (2010). The new lives of teachers. Routledge.

Dicke, T., Parker, P. D., Marsh, H. W., Kunter, M., Schmeck, A., \& Leutner, D. (2014). Self-efficacy in classroom management, classroom disturbances, and emotional exhaustion: A moderated mediation analysis of teacher candidates. Journal of Educational Psychology, 106(2), 569-583. https://doi.org/10..1037/a0035504

Dorman, J. P. (2003). Relationship between school and classroom environment and teacher burnout: A LISREL analysis. Social Psychology of Education, 6, 107-127. https://doi.org/110.1023/A:1023296126723

Eslami, Z. R., \& Fatahi, A. (2008). Teachers' sense of self-efficacy, English proficiency, and instructional strategies: A study of nonnative EFL teachers in Iran. TESL-EJ, 11(4), 1-19.

Evers, W. J. G., Brouwers, A., \& Tomic, W. (2002). Burnout and self-Efficacy: A study on teachers' beliefs when implementing an innovative educational system in the Netherlands. British Journal of Educational Psychology, 72, 227-45. https://doi.org/10.1348/000709902158865

Farber, B. A. (2000). Treatment strategies for different types of teacher burnout. Journal of Clinical Psychology, 56(5), 675-689.

Freudenberger, H. J. (1974). Staff burnout. Journal of Social Issues, 30, 159-165. https://doi. org/10.1111/j.1540-4560.1974.tb00706.x

Friedman, I. A., \& Farber, B. A. (1992). Professional self-concept as a predictor of teacher burnout. Journal of Educational Research, 86, 28-35. https://doi.org/10.1080/00220671.1992.9941824

Gay, L. R., Mills, G. E., \& Airasian, P. (2009). Educational research: Competencies for analysis and applications (9 $9^{\text {th }}$ ed.). Pearson Education.

Greenglass, E. R., \& Burke, R. J. (1988). Career orientations and psychological burnout in teachers. Psychological Reports, 63, 107-116. https://doi.org/10.2466/pr0.1988.63.1.107

Hanushek, E. A. (2007). The single salary schedule and other issues of teacher pay. Peabody Journal of Education, 82(4), 574-586. https://doi.org/10.1080/01619560701602975

Hong, J. Y. (2012). Why do some beginning teachers leave the school, and others stay? Understanding teacher resilience through psychological lenses. Teachers and Teaching: Theory and Practice, 18(4), 417-440. https:// doi.org/10.1080/13540602.2012.696044

Jedynak, M. (2011). Teaching experience and its role in foreign language teachers' anxiety. Acta Neophilologica, $13,59-72$.

Jennett, H. K., Harris, S. L., \& Mesibov, G. B. (2003). Commitment to philosophy, teacher efficacy, and burnout among teachers of children with autism. Journal of Autism and Developmental Disorders, 33, 583-593. https:// doi.org/10.1023/B:JADD.0000005996.19417.57

Kahn, J. H., Schneider, K. T., Jenkins-Henkelman, T. M., \& Moyle, L. L. (2006). Emotional social support and job burnout among high-school teachers: Is it all due to dispositional affectivity? Journal of Organizational Behavior, 27, 793-807. https://doi.org/10.1002/job.397

Kay-Eccles, R. (2012). Meta-analysis of the relationship between coworker social support and burnout using a two level hierarchical linear model. Western Journal of Nursing Research, 34, 1062-1063. https://doi. org/10.1177/0193945912453684

Klassen, R. M., \& Chiu, M. M. (2010). Effects on teachers' self-efficacy and job satisfaction: Teacher gender, years of experience, and job stress. Journal of Educational Psychology, 102, 41-756. https://doi.org/10.1037/ a0019237

Klassen, R. M., Tze, V. M. C., Betts, S. M., \& Gordon, K. A. (2011). Teacher efficacy research 1998-2009: Signs of progress or unfulfilled promise? Educational Psychology Review, 23(1), 21-43. https://doi.org/10.1007/ s10648-010-9141-8

Klusmann, U., Kunter, M., Trautwein, U., Lüdtke, O., \& Baumert, J. (2008). Engagement and emotional exhaustion in teachers: Does the school context make a difference? Applied Psychology: An International Review, 57, 127151. https://doi.org/10.1111/j.1464-0597.2008.00358.x

Kokkinos, C. M. (2007). Job stressors, personality, and burnout in primary school teachers. British Journal of Educational Psychology, 77(1), 229-243.https://doi.org/10.1348/000709905X90344

Küçüksüleymanoğlu, R. (2011). Burnout syndrome levels of teachers in special education schools in Turkey. 
International Journal of Special Education, 26(1), 53-63.

Larson-Hall, J. (2010). A guide to doing statistics in second language research using SPSS. Routledge.

Lau, P. S., Yuen, M. T., \& Chan, R. M. (2005). Do demographic characteristics make a difference among Hong Kong secondary school teachers? Social Indicators Research, 71, 491-516.

Lim, N., Kim, E. K., Kim, H., Yang, E., \& Lee, S. (2010). Individual and work-related factors influencing burnout of mental health professionals: A meta-analysis. Journal of Employment Counseling, 47, 86-96. https://doi. org/10.1002/j.2161-1920.2010.tb00093.x

Mackey, A., \& Gass, S. (2005). Second language research: Methodology and design. Lawrence Erlbaum Associates Publishers.

Mardani, N., Baghelani, E., \& Azizi, R. (2015). Exploring the relationship between self-efficacy and burnout: The Case of Iranian EFL teachers. Cumhuriyet Üniversitesi Fen Edebiyat Fakültesi Fen Bilimleri Dergisi, 36(3), 3538-3548.

Maslach, C. (1982). Burnout: The cost of caring. Prentice Hall.

Maslach, C. (2015). Psychology of burnout. International Encyclopedia of the Social and Behavioral Sciences, 2, 929-932.

Maslach, C., \& Jackson, S. E. (1985). The role of sex and family variables in burnout. Sex Roles, 12, 837-851.

Maslach, C., \& Jackson, S. E. (1986). Maslach burnout inventory manual ( $2^{\text {nd }}$ ed.). Consulting Psychologist Press.

Maslach, C., Jackson, S. E, \& Leiter, M. P. (1996). MBI: The Maslach Burnout Inventory Manual (3rd ed.). Consulting Psychologists Press.

Maslach, C., Jackson, $\quad$ S. E., \& Schwab, R. L. (1986). Maslach Burnout Inventory - Educators Survey (MBI-ES). In C. Maslach, S. E. Jackson, \& M. P. Leiter. (Eds.), MBI Manual (3 $3^{\text {rd }}$ ed., pp. 191-218). Consulting Psychologist Press.

Maslach, C., Schaufeli, W. B., \& Leiter, M. P. (2001). Job burnout. Annual Review of Psychology, 52, 397-422. https:// doi.org/10.1146/annurev.psych.52.1.397

McCarthy, C., Lambert, R., O’Donnell, M., \& Melendres, L. (2009). The relation of elementary teachers' experience, stress, and coping resources to burnout symptoms. The Elementary School Journal, 109, 1-19. https://doi.org/ $10.1086 / 592308$

Mede, E. (2009). An analysis of relations among personal variables, perceived self-efficacy and social support on burnout among Turkish EFL teachers. Inonu University Journal of the Faculty of Education, 10(2), 39-52.

Motallebzadeh, K., Ashraf, H., \& Tabatabaee-Yazdi, M. (2014). On the relationship between Iranian EFL teachers' burnout and self-efficacy. Procedia-Social and Behavioral Sciences, 98, 1255-1262. https://doi.org/10.1016/j. sbspro.2014.03.541

Ortero Lopez, J. M., Castro Bolaño, C. C., Santiago Mariño, M. J, \& Villardefrancos Pol, E. (2010). Exploring stress, burnout, and job satisfaction in secondary school teachers. International Journal of Psychology and Psychological Therapy, 10(1), 107-123.

Ozkara, B. (2019). An investigation into the relationship between Turkish EFL teachers' self-efficacy and burnout level. Journal of Family Counseling and Education, 4(1), 12-24. dhttps://doi.org/10.32568/jfce.504499

Perrewé, P. L., Hochwarter, W. A., Rossi, A. M., Wallace, A., Maignan, I., Castro, S. L., et al. (2002). Are work stress relationships universal? A nine-region examination of role stressors, general self-efficacy, and burnout. Journal of International Management, 8, 163-187. https://doi.org/ 10.1016/S1075-4253(02)00052-2

Poulin, J., \& Walter, C. (1993). Social workers' burnout: A longitudinal study. Social Work Research \& Abstracts, 29(4), 5-11. https://doi.org/10.1093/swra/29.4.5

Purvanova, R. K., \& Muros, J. P. (2010). Gender differences in burnout: A meta-analysis. Journal of Vocational Behavior, 77, 168-185.

Reeve, J., \& Su, Y-L. (2014). Teacher motivation. In M. Gagné (Ed.), The Oxford handbook of work engagement, motivation, and self-determination theory (pp. 349-362). Oxford University Press.

Robson, C. (1993). Real world research: A resource for social scientists and practitioner-researchers. Blackwell.

Roohani, A., \& Dayeri, Kh. (2019). On the relationship between Iranian EFL teachers' burnout and motivation: A mixed methods study. Iranian Journal of Language Teaching Research (IJLTR) 7,1,77-99.

Sari, H. (2004). An analysis of burnout and job satisfaction among Turkish special school head teachers and teachers, and the factors affecting their burnout and job satisfaction. Educational Studies, 30(3), 291-306. https://doi.org/10.1080/0305569042000224233

Schwarzer, R., \& Hallum, S. (2008). Perceived teacher self-efficacy as a predictor of job stress and burnout: Mediation analyses. Applied Psychology, 57, 152-171. https://doi.org/10.1111/j.1464-0597.2008.00359x

Schwarzer, R., Schmitz, G. S., \& Tang, C. (2000). Teacher burnout in Hong Kong and Germany: A cross-cultural validation of the Maslach Burnout Inventory. Anxiety, Stress, and Coping, 13 (3), 309-326. https://doi. 
org/10.1080/10615800008415730

Skaalvik, E. M., \& Skaalvik, S. (2007). Dimensions of teacher self-efficacy and relations with strain factors, perceived collective teacher efficacy, and teacher burnout. Journal of Educational Psychology, 99, 611-625. https://doi.org/10.1037/0022-0663.99.3.611

Skaalvik, E. M., \& Skaalvik, S. (2010). Teacher self-efficacy and teacher burnout: A study of relations. Teaching and Teacher Education, 26, 1059-1069. https://doi.org/10.1016/j.tate.2009.11.001

Smith, M., \& Bourke, S. (1992). Teacher stress: Examining a model based on context, work load, and satisfaction. Teaching and Teacher Education 8(1), 31-46. https://doi.org/10.1016/0742-051X(92)90038-5

Tschannen-Moran, M., \& Woolfolk Hoy, A. (2001). Teacher efficacy: Capturing an elusive construct. Teaching and Teacher Education, 17, 783-805. https://doi.org/10.1016/S0742-051X(01)00036-1

Tschannen-Moran, M., Woolfolk Hoy, A., \& Hoy, W. K. (1998). Teacher efficacy: Its meaning and measure. Review of Educational Research, 68, 202-248.

Unsworth, K. L., \& Mason, C. M. (2012). Help yourself: The mechanisms through which a self- leadership intervention influences strain. Journal ofOccupational Health Psychology, 17, 235-245. https://doi.org/10.1037/ a0026857

Van Tonder, C. L., \& Williams, C. (2009). Exploring the origins of burnout among secondary educators. SA Journal of Industrial Psychology, 35(1), 204-218.

Woolfolk, A. (2004). Educational Psychology (9th ed.). Allyn and Bacon.

Yang, H., \& Farn, C. K. (2005). An investigation of the factors MIS student burnout in technical- vocational college. Computer Human Behavior, 21, 917-932. https://doi.org/10.1016/j.chb.2004.03.001 


\section{ALI ROOHANI, MEHDI IRAVANI}

\section{Appendix}

\section{Semi-Structured Interview Questions}

1. Do you feel tired from your work? If so, why?

2. Have you ever thought of changing your job? If so, why?

3. Have you ever felt tired of teaching at school? If so, how often?

4. Can you talk about some of your achievements as an EFL teacher?

5. Do you think you are successful in your job, managing the classroom and behaviors of your students, controlling disruptive behavior...? If so, how and how much?

6. Is it important for you when your students learn/do not English? Why and how much?

7. Can you get your students to believe that they can do well in learning English at school?

8. Can you change your students' attitudes/views toward learning English? Why and how much? 